Article

\title{
A Cyclic Altered Peptide Analogue Based on Myelin Basic Protein 87-99 Provides Lasting Prophylactic and Therapeutic Protection Against Acute Experimental Autoimmune Encephalomyelitis
}

\author{
Mary Emmanouil ${ }^{1}$, Vivian Tseveleki ${ }^{1}$, Iro Triantafyllakou ${ }^{2}$, Agathi Nteli ${ }^{2}$, Theodore Tselios ${ }^{2, *}$ \\ and Lesley Probert ${ }^{1, *}$ (iD \\ 1 Laboratory of Molecular Genetics, Hellenic Pasteur Institute, 127 Vasilissis Sophias Ave., \\ 11521 Athens, Greece; emmanouilm@pasteur.gr (M.E.); tseveleki@gmail.com (V.T.) \\ 2 Department of Chemistry, University of Patras, 26504 Patras, Greece; irotriant@gmail.com (I.T.); \\ anteli@upatras.gr (A.N.) \\ * Correspondence: ttselios@upatras.gr (T.T.); lesley.probert@gmail.com (L.P.); \\ Tel.: +30-261-0997905 (T.T.); +30-210-6478866 (L.P.)
}

Received: 5 December 2017; Accepted: 24 January 2018; Published: 31 January 2018

\begin{abstract}
In this report, amide-linked cyclic peptide analogues of the 87-99 myelin basic protein (MBP) epitope, a candidate autoantigen in multiple sclerosis (MS), are tested for therapeutic efficacy in experimental autoimmune encephalomyelitis (EAE). Cyclic altered peptide analogues of $\mathrm{MBP}_{87-99}$ with substitutions at positions 91 and/or 96 were tested for protective effects when administered using prophylactic or early therapeutic protocols in $\mathrm{MBP}_{72-85}$-induced EAE in Lewis rats. The Lys ${ }^{91}$ and Pro $^{96}$ of $\mathrm{MBP}_{87-99}$ are crucial T-cell receptor (TCR) anchors and participate in the formation of trimolecular complex between the TCR-antigen (peptide)-MHC (major histocompability complex) for the stimulation of encephalitogenic $\mathrm{T}$ cells that are necessary for EAE induction and are implicated in MS. The cyclic peptides were synthesized using Solid Phase Peptide Synthesis (SPPS) applied on the 9-fluorenylmethyloxycarboxyl/tert-butyl Fmoc/tBu methodology and combined with the 2-chlorotrityl chloride resin (CLTR-Cl). Cyclo(91-99)[Ala $\left.{ }^{96}\right] \mathrm{MBP}_{87-99}$, cyclo(87-99)[Ala $\left.{ }^{91,96}\right] \mathrm{MBP}_{87-99}$ and cyclo(87-99)[Arg $\left.{ }^{91}, \mathrm{Ala}^{96}\right] \mathrm{MBP}_{87-99}$, but not wild-type linear $\mathrm{MBP}_{87-99}$, strongly inhibited $\mathrm{MBP}_{72-85}$-induced EAE in Lewis rats when administered using prophylactic and early therapeutic vaccination protocols. In particular, cyclo(87-99)[Arg ${ }^{91}$, Ala $\left.{ }^{96}\right] \mathrm{MBP}_{87-99}$ was highly effective in preventing the onset and development of clinical symptoms and spinal cord pathology and providing lasting protection against EAE induction.
\end{abstract}

Keywords: myelin basic protein (MBP); experimental autoimmune encephalomyelitis (EAE); multiple sclerosis (MS); altered peptide ligands (APLs); cyclic peptides

\section{Introduction}

Multiple sclerosis (MS) is a chronic immune-mediated disease of the central nervous system (CNS) causing demyelination and progressive neuronal damage [1]. Experimental autoimmune encephalomyelitis (EAE) is a well-characterized experimental model for MS that is induced by immunization of susceptible animal strains with myelin proteins or immunodominant peptide epitopes from proteins such as myelin basic protein (MBP), myelin oligodendrocyte glycoprotein (MOG), and proteolipid protein (PLP). EAE recapitulates the autoimmune T cell-mediated attack on CNS myelin that is believed to underlie MS pathogenesis [2], and is a valuable in vivo system for the design and preclinical testing of experimental therapeutics intended for MS [3]. MBP is a candidate autoantigen in MS [4-8], with the $\mathrm{MBP}_{86-95}$ peptide representing an immunodominant epitope centre 
for human autoantibody binding and T-cell recognition [9], and this epitope has been used for the development of selective peptide-specific immunotherapeutics for MS [10-14].

Altered peptide ligands (APLs) based on the $\mathrm{MBP}_{86-95}$ core epitope, in which primary T-cell receptor (TCR) anchors Lys and Pro at positions 91 and 96, are replaced with Arg and/or Ala, respectively, protecting mice against EAE $[15,16]$ and induce differential activation of human T-cell lines [11]. APL stimulate differential T-cell receptor (TCR) signaling and cellular responses compared to wild-type peptides, and can antagonize [17], anergize [18] or partially activate [19] T cells. They can deviate immune responses away from autoimmune Th1 responses towards allergic Th2 responses, and thereby ameliorate EAE $[20,21]$. Clinical trials using such APL in MS patients provided important proof-of-principle that immune deviation of MBP-specific T-cell responses impacts disease severity, but studies were halted because of safety concerns associated with immune activation [12,13]. A novel alternative approach to the development of peptide therapeutics for autoimmune disease is the design and synthesis of cyclic peptides. Peptide cyclization restricts the conformational flexibility of linear counterparts and results in increased metabolic stability and receptor selectivity, thereby providing a better pharmacological profile, and possibly the ability to alter TCR signaling outcomes [22]. The design of cyclic peptide analogues by connecting residues that are least important for activity, without causing drastic structural changes in bioactive conformation of the peptide, results in a rigid geometry and better bioavailability of cyclic peptides compared to the linear ones. Over the last years our group has been involved in the rational design and synthesis of bioactive mutated cyclic peptides based on the $\mathrm{MBP}_{83-99}$ core epitope [23-28], and incorporating previous knowledge concerning derived APLs that exhibit immune-modulatory function [6,11,12].

We chose the $\mathrm{MBP}_{87-99}$ sequence as a model for the rational design of cyclic APL design because it is a candidate auto-antigen in MS, and induces T-cell responses and EAE in Lewis rats and SJL mice $[24,28]$. Peptide cyclization is achieved between the $\mathrm{N}$ and $\mathrm{C}$ terminal or the side chain amino group of Lys ${ }^{91}$ and the $C$ terminal via an amide bond, while the Lys and Pro at positions 91 and 96, respectively, are replaced with Arg and/or Ala $[29,30]$. We show previously that cyclic $\mathrm{MBP}_{87-99}$ analogues bind efficiently to HLA-DR4 and are more stable to hydrolysis by lysosomal enzymes and cathepsin $\mathrm{D}$, compared to their linear counterparts $[25,26]$, and that the three cyclic mutated analogues of $\mathrm{MBP}_{87-99}$ used here, specifically cyclo(91-99)[Ala ${ }^{96}{ } \mathrm{MBP}_{87-99}$ [24], cyclo(87-99)[Ala ${ }^{91}$, $\mathrm{Ala}^{96}{ }^{9} \mathrm{MBP}_{87-99}$ [26], and cyclo(87-99)[Arg ${ }^{91}, \mathrm{Ala}^{96}{ }^{9} \mathrm{MBP}_{87-99}$ [24], ameliorate EAE in Lewis rats when co-administered with $\mathrm{MBP}_{72-85}$ during immunization. However, the mechanism of action of cyclic peptide analogues, whether they protect against EAE passively by competing with $\mathrm{MBP}_{72-85}$ for $\mathrm{MHC}$ class II binding, actively through induction of a Th1/Th2 shift or regulatory T-cell differentiation, or a different mechanism, remains to be determined. In the present study, we investigated the ability of $\mathrm{MBP}_{87-99}$ cyclic mutated analogues to protect against EAE induced in Lewis rats by $\mathrm{MBP}_{72-85}$ when administered separately from the immunizing antigen using prophylactic (vaccination) and therapeutic protocols, thereby minimizing the possibility of direct competition between $\mathrm{MBP}_{72-85}$ and cyclic MBP $87-99$ analogues for MHC class II binding. We also investigated whether immunization with cyclic $\mathrm{MBP}_{87-99}$ analogues led to formation of immunological memory that allowed protection to persist over time.

\section{Results}

\subsection{Solid-Phase Peptide Synthesis and Cyclization of the Mutated Peptide Analogues}

The synthetic procedure of linear peptide analogues and subsequently their cyclization is presented in Scheme 1. The first $N^{\alpha}$-9-fluorenylmethyloxycarboxyl (Fmoc) protected amino acid, was esterified to the 2-chlorotrytil chloride (CLTR) resin in the presence of $N, N$-diisopropylethylamine (DIPEA), followed by Fmoc deprotection. The peptide bonds were accomplished using 1hydroxybenzotriazole (HOBt) and $N, N^{\prime}$-diisopropylcarbodiimide (DIC) as coupling reagents. The side chains of amino acids were protected as follows: Trt for Asn, His, Pbf for Arg and tBu for Thr. In the 
case of cyclo(91-99)[Ala $\left.{ }^{96}\right] \mathrm{MBP}_{87-99}$, in which the side chain amine group of Lys at position 91 and C-terminal carboxyl group formed an amide bond, the 4-methyltrityl (Mtt) group was used for protection. This group was removed upon treatment of protected peptide-resin with the splitting mixture dichloromethane (DCM)/1,1,1,3,3,3-hexafluoro-2-propanol (HFIP) (7/3) that used to cleave the peptide from the resin. The use of the 2-chlorotrityl chloride resin, as well as of mild cleaving conditions, allowed the protected peptides to release from the resin and the subsequent cyclization of the desired protected peptides. Cyclization was achieved using $O$-(benzotriazol-1-yl)- $N, N, N^{\prime}, N^{\prime}-$ tetramethyluronium tetrafluoroborate (TBTU), 1-hydroxy-7-azabenzotriazole (HOAt) and 2,4,6collidine (2,4,6-trimethylpyridine). The final deprotection of each peptide was achieved using trifluoroacetic acid (TFA) in DCM in the presence of scavengers. The purification was achieved using semi preparative, reverse phase high performance liquid chromatography (RP-HPLC) while the peptide purity was assessed by analytical RP-HPLC and by electron spray ionization mass spectrometry (ESI-MS; Supplementary Materials).

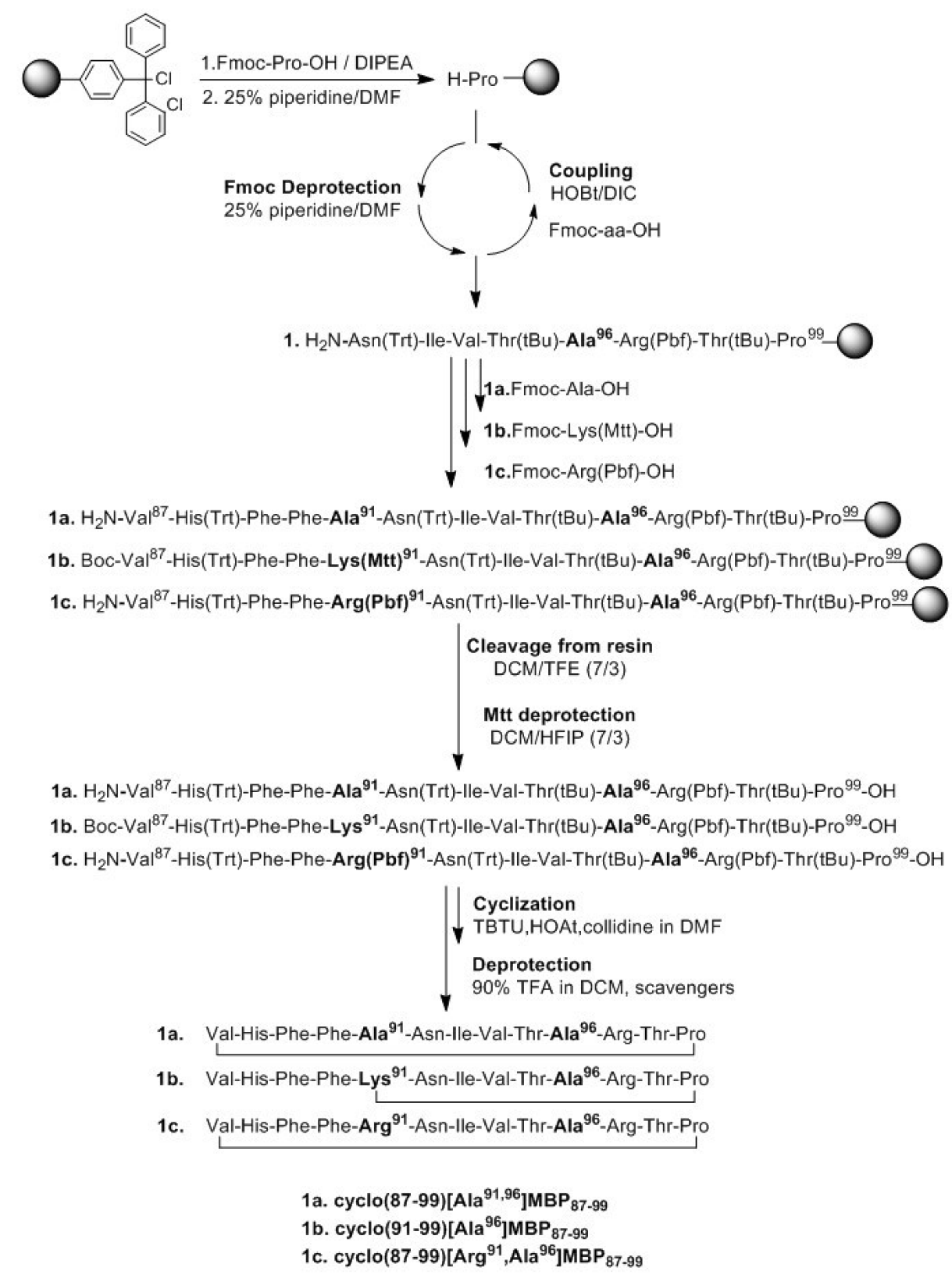

Scheme 1. Synthetic procedure of cyclic peptide analogues of myelin basic protein (MBP). 


\subsection{Prophylactic or Early Therapeutic Delivery of Cyclic Mutated $M_{B} P_{87-99}$ Analogues} Ameliorates $\mathrm{MBP}_{72-85}-\mathrm{EAE}$

To test the ability of the cyclic altered $\mathrm{MBP}_{87-99}$ analogues to ameliorate EAE when administered in prophylactic or early therapeutic protocols, we administered them to Lewis rats s.c., two days before or two days after, respectively, immunization with $\mathrm{MBP}_{72-85}$ for the induction of EAE. First we excluded the possibility that wild-type linear peptide, $\mathrm{MBP}_{87-99}$, altered the development of EAE. Administration of linear $\mathrm{MBP}_{87-99}(500 \mu \mathrm{g})$ two days before, or two days after, immunization with $\mathrm{MBP}_{72-85}$ for the induction of EAE, did not alter the development of acute monophasic EAE compared to nontreated animals (Figure 1A). In contrast, administration of the cyclic altered analogues

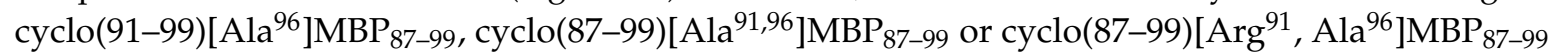
$(500 \mu \mathrm{g})$, either two days before, or two days after, immunization with $\mathrm{MBP}_{72-85}$ all markedly ameliorated the development of EAE (Figure 1B,C). We selected one of the cyclic analogues, cyclo(87-99)[Arg $\left.{ }^{91}, \mathrm{Ala}^{96}\right] \mathrm{MBP}_{87-99}$, for further studies (Table 1). To exclude the possibility that cyclo(87-99)[Arg ${ }^{91}$, Ala ${ }^{96}{ } \mathrm{MBP}_{87-99}$ has EAE-inducing potential, we immunized mice with $30 \mu \mathrm{g}$ or $500 \mu \mathrm{g}$ analogue using the EAE immunization protocol, and confirmed that neither amount induced EAE (Figure 1D).
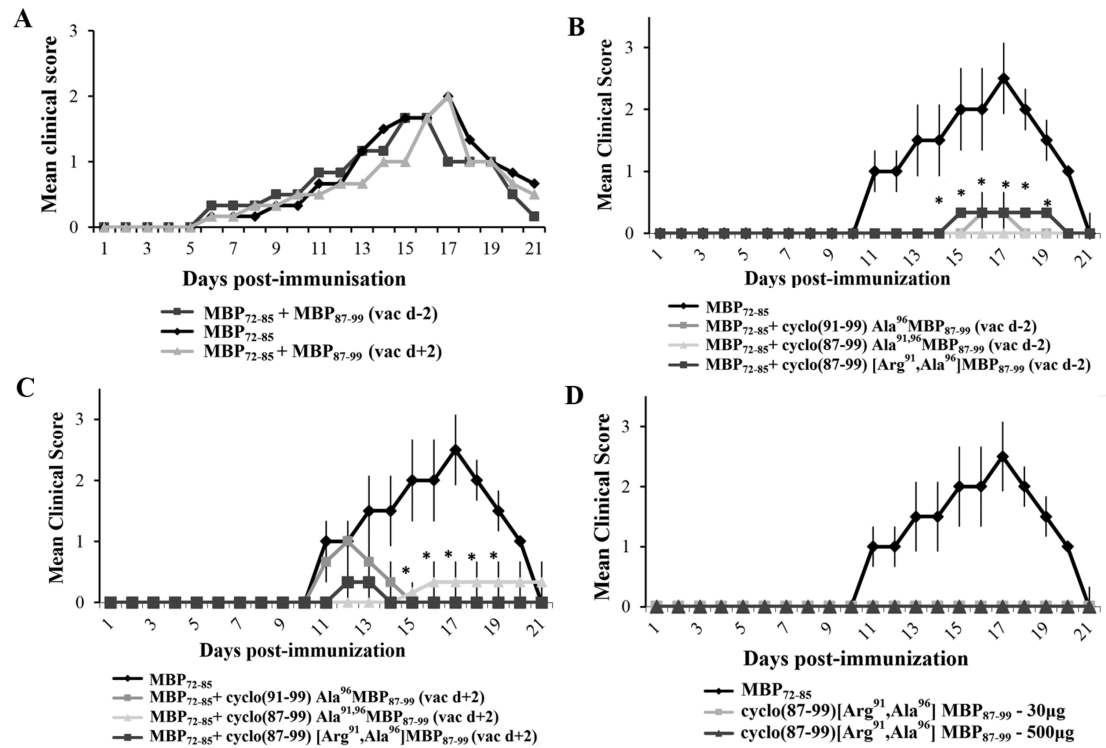

Figure 1. Administration of cyclic myelin basic protein (MBP) 87-99 peptide analogues using prophylactic or therapeutic protocols ameliorates the development of $\mathrm{MBP}_{72-85}$-induced experimental autoimmune encephalomyelitis (EAE) in female Lewis rats. (A) Mean clinical scores of $\mathrm{MBP}_{72-85}$-EAE in groups of rats that were treated subcutaneously (s.c.) with wild type linear $\mathrm{MBP}_{87-99}$, as control, either 2 days before (prophylactic) or 2 days after (therapeutic) immunization with $\mathrm{MBP}_{72-85}(30 \mu \mathrm{g})$ for the induction of EAE ( $n=3$ for each group); $(\mathbf{B}, \mathbf{C})$ Mean clinical scores of $\mathrm{MBP}_{72-85}$-EAE in groups of rats that were treated s.c. with either cyclo(91-99)[Ala $\left.{ }^{96}\right] \mathrm{MBP}_{87-99}$, cyclo(87-99)[Ala $\left.{ }^{91,96}\right] \mathrm{MBP}_{87-99}$

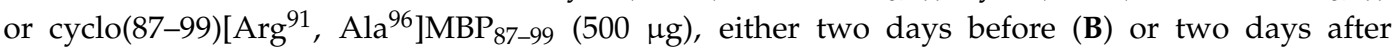
(C) immunization with $\mathrm{MBP}_{72-85}(30 \mu \mathrm{g})$ for the induction of EAE ( $\mathrm{n}=3$ for each group); (D) Mean clinical scores of EAE in groups of rats that were immunized with $\mathrm{MBP}_{72-85}$ or cyclo(87-99)[Arg ${ }^{91}$, $\mathrm{Ala}^{96} \mathrm{MBP}_{87-99}$ (at $30 \mu \mathrm{g}$ and $500 \mu \mathrm{g}$ ), emulsified in complete Freund's adjuvant (CFA) for the induction of $\operatorname{EAE}\left(n=3\right.$ for $\mathrm{MBP}_{72-85} ; n=3$ for cyclic analogue). Data are from one (A,D, and experiments using cyclo(91-99)[Ala ${ }^{96} \mathrm{MBP}_{87-99}$ and cyclo(87-99)[Ala91,96] ${ }^{9} \mathrm{MBP}_{87-99}$ ), or one representative (experiment 1) of three (experiments using cyclo(87-99)[Arg ${ }^{91}$, Ala ${ }^{96}$ ] MBP $87-99$ ), independent experiments (total animals used: experiment $1, n=24$; experiment 2, $n=18$; experiment 3, $n=12$ ). Statistical significance after multigroup comparisons, using the Mann-Whitney test, is shown $(*, p<0.05)$. 
Table 1. Incidence, mean day of onset and mean maximal score of myelin basic protein 72-85 epitope $\left(\mathrm{MBP}_{72-85}\right)$-induced experimental autoimmune encephalomyelitis (EAE) in female Lewis rats, nonvaccinated (control) or vaccinated two days before (prophylactic) and two days after (early therapeutic) induction of EAE, with cyclo(87-99)[Arg91, Ala $\left.{ }^{96}\right] \mathrm{MBP}_{87-99}$, as shown in three independent experiments (experiments 1-3). Data are also shown (experiment 4) from $\mathrm{MBP}_{72-85}$-EAE in groups of rats that were treated prophylactically 23 days before immunization. Mean day of onset and mean maximal score are presented as mean $\pm \mathrm{SEM}$.

\begin{tabular}{cccc}
\hline Rats & Incidence & Mean Day of Onset & Mean Maximal Score \\
\hline Expt1 & & & \\
Control & $3 / 3(100 \%)$ & $11.00 \pm 1.08$ & $2.60 \pm 0.27$ \\
Prophylactic vac d -2 & $1 / 3(33.3 \%)$ & 15.00 & $1.00 \pm 0.27$ \\
Therapeutic vac d +2 & $1 / 3(33.3 \%)$ & 12.00 & $1.00 \pm 0.27$ \\
\hline Expt2 & & & \\
Control & $6 / 6(100 \%)$ & $8.16 \pm 0.15$ & $3.00 \pm 0.35$ \\
Prophylactic vac d -2 & $4 / 6(66.6 \%)$ & $9.25 \pm 0.45$ & $0.41 \pm 0.14$ \\
Therapeutic vac d 2 & $5 / 6(83.4 \%)$ & $10.40 \pm 1.25$ & $1.25 \pm 0.32$ \\
\hline Expt3 & & & \\
Control & $6 / 6(100 \%)$ & $11.30 \pm 0.45$ & $2.60 \pm 0.34$ \\
Prophylactic vac d -2 & $5 / 6(83.4 \%)$ & $12.00 \pm 0.32$ & $1.58 \pm 0.41$ \\
\hline Expt4 & & & \\
Control & $4 / 4(100 \%)$ & $9.30 \pm 0.27$ & $3.33 \pm 0.13$ \\
Prophylactic vac d -23 & $4 / 4(100 \%)$ & $12.75 \pm 0.41$ & $1.87 \pm 0.44$ \\
\hline
\end{tabular}

To investigate whether amelioration of the clinical symptoms of EAE by the cyclic peptide analogues was associated with reduction of neuropathology, we chose one of the analogues, cyclo(87-99)[Arg $\left.{ }^{91}, \mathrm{Ala}^{96}\right] \mathrm{MBP}_{87-99}$, and administered it to $\mathrm{MBP}_{72-85}$-EAE rats using prophylactic and early therapeutic protocols. Rats were sacrificed on day 17, at the peak of clinical symptoms in the untreated control group (Figure 1), and spinal cords analyzed by standard histopathological techniques. Untreated EAE rats showed characteristic features of $\mathrm{MBP}_{72-85}$-EAE in Lewis rats; infiltration of the spinal cord parenchyma by immune cells, without white matter demyelination or axonal damage (Figure 2A, upper row). In contrast, treated rats showed no infiltration of the spinal cord parenchyma and few $\mathrm{T}$ cells in the meninges (Figure 2A, bottom row).
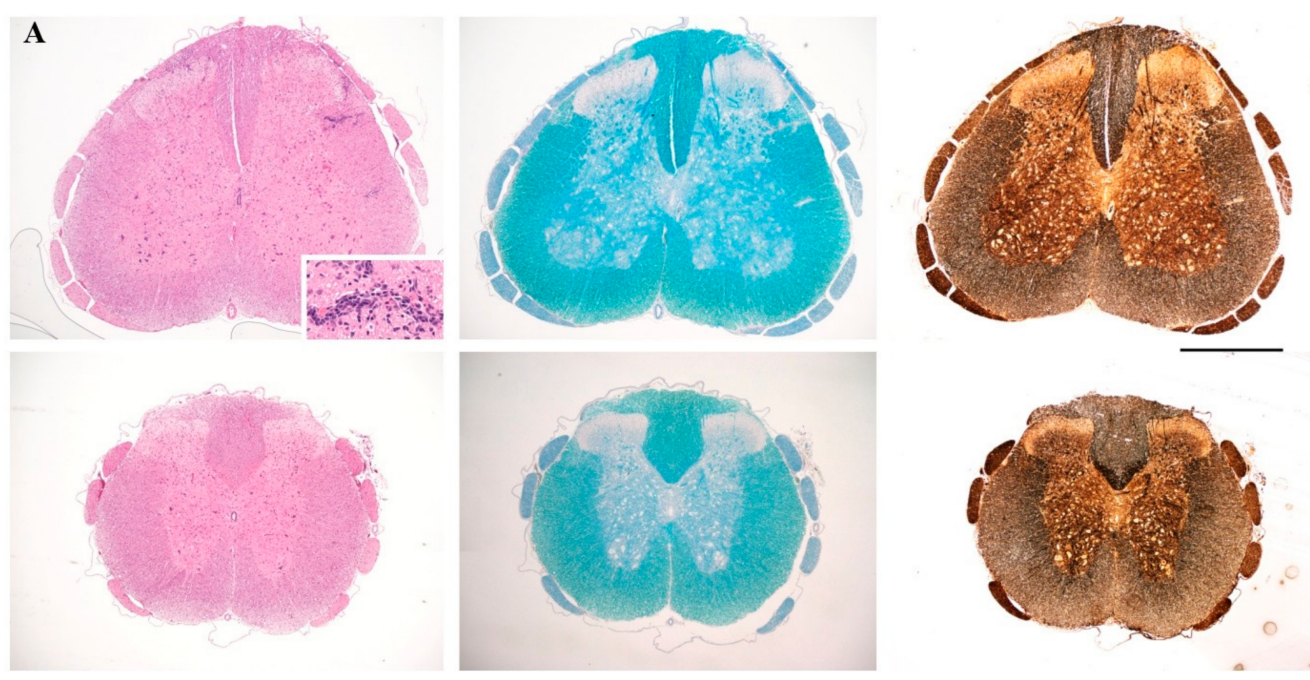

Figure 2. Cont. 
B

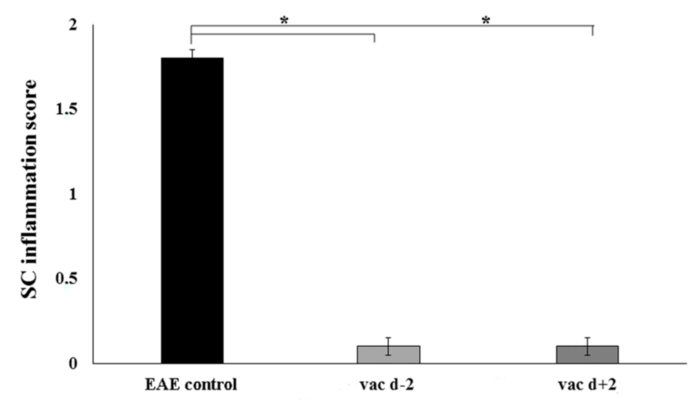

Figure 2. (A) Neuropathological analysis of spinal cord sections taken on day 17 following immunization, from representative nonvaccinated control rats (top) and rats vaccinated, two days before (prophylactic) induction of myelin basic protein $72-85$ epitope $\left(\mathrm{MBP}_{72-85}\right.$ )-induced experimental autoimmune encephalomyelitis (EAE), with cyclo(87-99)[Arg ${ }^{91}$, Ala ${ }^{96}$ ]MBP 87-99 (bottom). Sections were stained with H\&E for inflammation (left panels), Luxol Fast Blue for myelin (central panels), and Bielschowsky's silver stain for axons (right panels). Inset shows inflammatory infiltrates in the spinal cord parenchyma. Representative sections from 1 animal per group are shown $(n=3$ for each group). Scale bar $1 \mathrm{~mm}$; (B) Semi-quantitative representation of spinal cord (SC) inflammation in nonvaccinated EAE control rats (EAE control), rats vaccinated with cyclo(87-99)[Arg91 , Ala $\left.{ }^{96}\right] \mathrm{MBP}_{87-99}$, 2 days before $(\operatorname{vac} \mathrm{d}-2)$ and 2 days after $(\operatorname{vac} \mathrm{d}+2)$ induction of $\mathrm{MBP}_{72-85}$-EAE. Pathological changes of spinal cord sections were scored as inflammatory infiltrates $/ \mathrm{mm}^{2}$ of tissue for the three groups of rats ( $n=3$ for each group). Statistical significance after multi-group comparisons, using the Mann-Whitney test, is shown $(*, p<0.05)$.

\subsection{Cyclic Altered $M B P_{87-99}$ Analogues Induce T Cell Proliferation Responses}

To investigate whether rats treated with cyclo(87-99)[Arg ${ }^{91}$, $\left.\mathrm{Ala}^{96}\right] \mathrm{MBP}_{87-99}$ mounted antigen-specific T-cell responses, we measured ex vivo T-cell proliferation responses to $\mathrm{MBP}_{72-85}$ agonist and the cyclic $\mathrm{MBP}_{87-99}$ analogues in DLN cells and splenocytes isolated on day 10 p.i. from EAE rats from the different treatment groups. As expected, control vehicle-treated rats immunized with $\mathrm{MBP}_{72-85}$ for the induction of EAE, but not treated with cyclic analogue, showed T-cell proliferation responses to $\mathrm{MBP}_{72-85}$ agonist (Figure 3A,B), but not to cyclo(87-99)[Arg ${ }^{91}$, $\mathrm{Ala}^{96} \mathrm{MBP}_{87-99}$ (Figure 3C,D). In contrast, rats that were treated prophylactically or therapeutically with cyclic analogue, showed strong T-cell responses to the analogue (Figure $3 \mathrm{C}, \mathrm{D}$ ) and mild responses to the $\mathrm{MBP}_{72-85}$ agonist (Figure 3A,B). These results suggest that $\mathrm{T}$ cells specific for cyclo(87-99)[Arg ${ }^{91}$, $\left.\mathrm{Ala}^{96}\right] \mathrm{MBP}_{87-99}$ do not inhibit T-cell responses to $\mathrm{MBP}_{72-85}$ agonist, when they are induced prior to or two days after immunization with the agonist. 
A

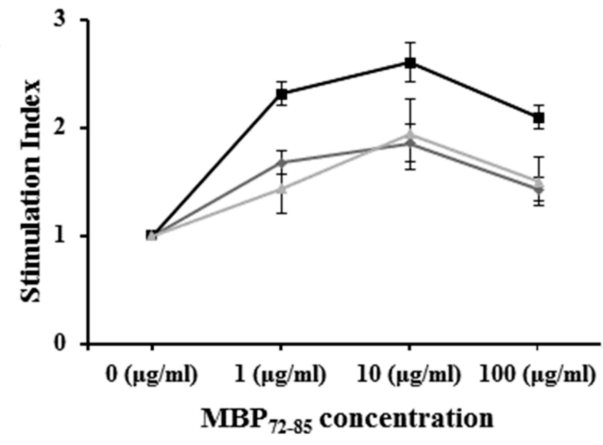

C

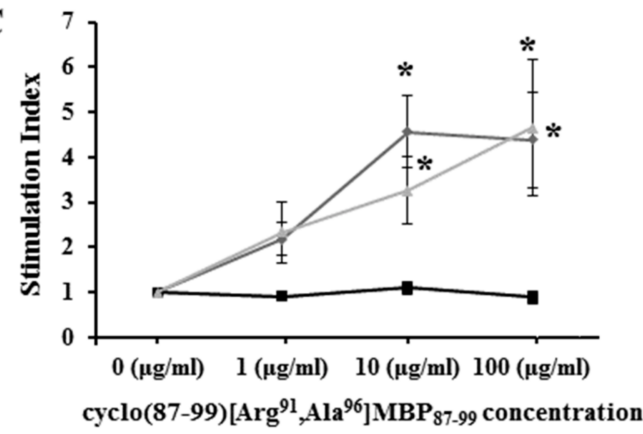

B

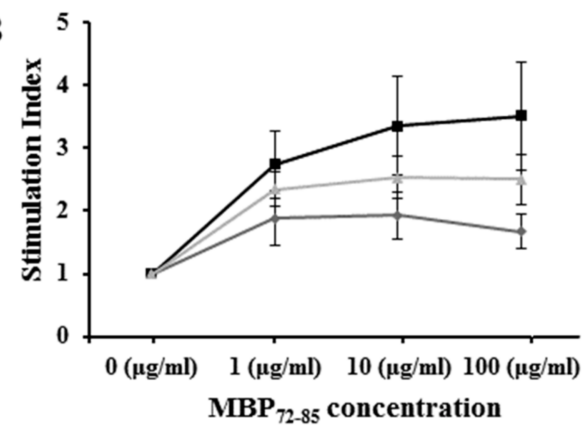

D

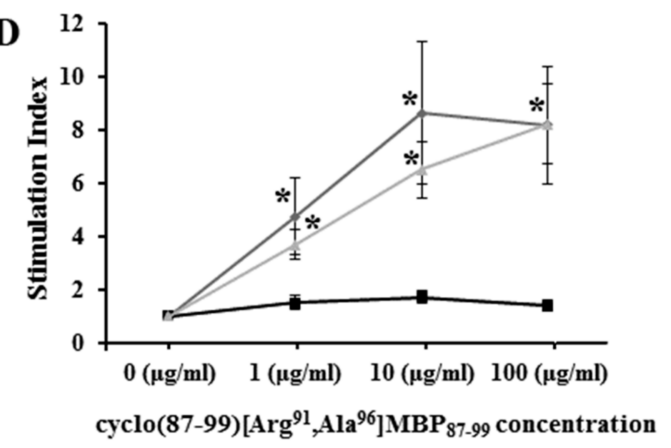

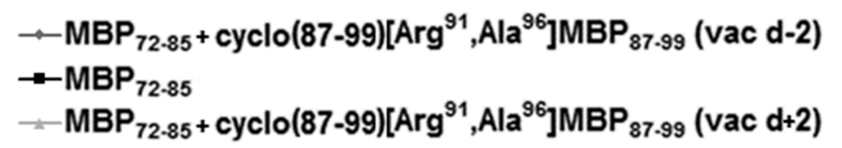

Figure 3. Proliferation of draining lymph node cells $(\mathbf{A}, \mathbf{C})$ and splenocytes $(\mathbf{B}, \mathbf{D})$ from control vehicle-treated rats, and rats treated with cyclic myelin basic protein (MBP) peptide analogue, cyclo(87-99)[Arg $\left.{ }^{91}, \mathrm{Ala}^{96}\right] \mathrm{MBP}_{87-99}$, isolated 10 days post-immunization with $\mathrm{MBP}_{72-85}$ for the induction of experimental autoimmune encephalomyelitis (EAE). Cells were stimulated ex vivo with increasing concentrations of linear $\mathrm{MBP}_{72-85}$ agonist (A,B) or cyclo(87-99)[Arg ${ }^{91}, \mathrm{Ala}^{96}{ }^{9} \mathrm{MBP}_{87-99}$ peptide $(\mathbf{C}, \mathbf{D})(n=4$ per group). Data are from one $(\mathbf{A}, \mathbf{B})$, or one representative of two $(\mathbf{C}, \mathbf{D})$ independent experiments. Statistical significance after pair-wise comparisons (using Student's $t$-test) of each experimental group with the control untreated, $\mathrm{MBP}_{72-85}$-induced $\mathrm{EAE}$ group is shown $(*, p<0.05)$.

2.4. Prophylactic Treatment with cyclo(87-99)[Arg $\left.{ }^{91}, A^{96}{ }^{96}\right] M B P_{87-99}$ Provides Lasting Protection Against $M B P_{72-85}$-Induced EAE

To determine the potential of cyclo(87-99)[Arg $\left.{ }^{91}, \mathrm{Ala}^{96}\right] \mathrm{MBP}_{87-99}$ treatment to provide long-term protection against $\mathrm{MBP}_{72-85}$-induced $\mathrm{EAE}$, we administered the cyclic analogue according to the prophylactic protocol. In one group of treated rats, EAE was induced as usual, two days later, by immunization with $\mathrm{MBP}_{72-85}$. As expected, rats treated with cyclo(87-99)[Arg ${ }^{91}, \mathrm{Ala}^{96}{ }^{9} \mathrm{MBP}_{87-99}$ showed markedly reduced clinical symptoms compared to untreated control rats (Figure 4A). In a second group of treated rats, EAE was induced 23 days later, by immunization with $\mathrm{MBP}_{72-85}$. Again, rats treated with cyclo(87-99)[Arg $\left.{ }^{91}, \mathrm{Ala}^{96}\right] \mathrm{MBP}_{87-99}$ showed markedly reduced clinical symptoms compared to untreated control rats immunized with $\mathrm{MBP}_{72-85}$ for the induction of EAE on day 23 of analogue treatment (Figure 4B). These results show that prophylactic treatment with cyclo(87-99)[Arg $\left.{ }^{91}, \mathrm{Ala}^{96}\right] \mathrm{MBP}_{87-99}$ provides lasting protection against $\mathrm{MBP}_{72-85}$-induced EAE. 
A

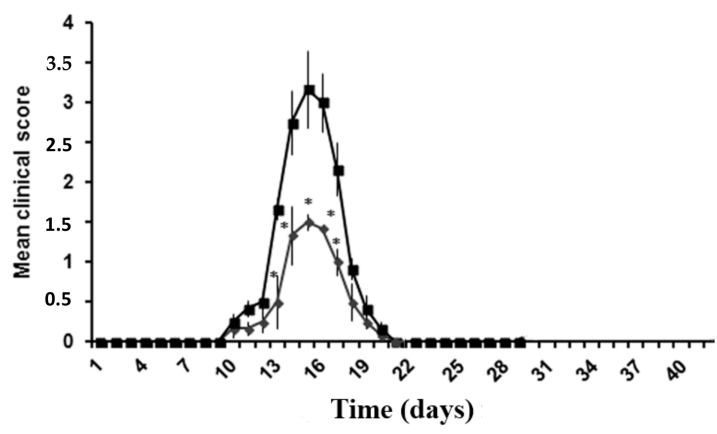

$\rightarrow$ cyclo87-99[Arg ${ }^{91}$, Ala $\left.^{96}\right]_{M B P}$ 87.99 $($ vac d-2) EAE d0

$\rightarrow-M^{2} P_{72.85}-E A E$ do

B

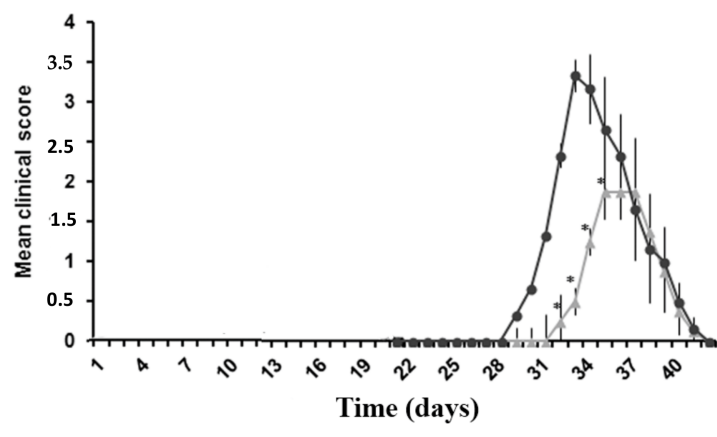

- cyclo87-99[Arg $\left.^{91}, \mathrm{Ala}^{96}\right]_{\mathrm{MBP}}{ }_{37.99}(\mathrm{vac} \mathrm{d}-2)$ EAE d21

$\rightarrow M P_{72-85}-$ EAE d21

Figure 4. Prophylactic administration of cyclic myelin basic protein (MBP) peptide analogue, cyclo(87-99)[Arg ${ }^{91}, \mathrm{Ala}^{96} \mathrm{MBP}_{87-99}$, provides lasting protection against the development of $\mathrm{MBP}_{72-85}$-induced experimental autoimmune encephalomyelitis (EAE) in female Lewis rats. Mean clinical scores of $\mathrm{MBP}_{72-85}$-induced EAE in groups of rats that were treated prophylactically subcutaneously (s.c.) with cyclo(87-99)[Arg ${ }^{91}, \mathrm{Ala}^{96}{ }^{9} \mathrm{MBP}_{87-99}(500 \mu \mathrm{g})$, either 2 days, or 23 days before immunization for $\mathrm{MBP}_{72-85}$-EAE. A first group of untreated and treated rats ( $n=6$ per group) was immunized with $\mathrm{MBP}_{72-85}$ for the induction of EAE on day 2 relative to treatment with cyclic analogue (day 0 on graph) (A), and a second group ( $n=4$ per group) on day 23 relative to treatment with cyclic analogue (day 21 on graph) (B). Data are from one experiment. Statistical significance after pair-wise comparisons between groups of rats (using Mann-Whitney test) is shown $\left(^{*}, p<0.05\right)$.

\section{Discussion}

Cyclic analogues of altered myelin peptide auto-antigens are known to inhibit the development of EAE induced by a different peptide auto-antigen, when co-administered with the immunizing antigen $[24,26]$. However, this experimental design confounds interpretation of the mechanism of disease inhibition. It is unclear whether cyclic APLs inhibit EAE passively by competing with the disease-inducing antigen for MHC class II binding, or actively through the differentiation of independent, disease-modulating T-cell population(s). The three cyclic mutant analogues used here, cyclo(91-99)[Ala $\left.{ }^{96}\right] \mathrm{MBP}_{87-99}$, cyclo(87-99)[Ala $\left.{ }^{91,96}\right] \mathrm{MBP}_{87-99}$ and cyclo(87-99)[Arg ${ }^{91}, \mathrm{Ala}^{96}{ }^{9} \mathrm{MBP}_{87-99}$, all efficiently bind human HLA-DR4, although with lower affinity than linear MBP $87-99[25,26]$. Peptide-binding studies with rodent MHC class II molecules have not been performed for the cyclic analogues, and the possibility that $\mathrm{MBP}_{87-99}$-based analogues compete with $\mathrm{MBP}_{72-85}$ antigen for MHC class II binding, when co-administered in Lewis rats, cannot be excluded. Cyclic peptide analogues might also regulate EAE by inducing Th1/Th2 immune deviation or stimulating inducible regulatory T cells (iTreg). Previous studies by our group showed that immunization of SJL mice 
with cyclo(87-99)[Ala ${ }^{91,96}{ }^{1} \mathrm{MBP}_{87-99}$ induces T-cell responses characterized by reduced IFN- $\gamma$ and increased IL-4 production compared to wild-type $\mathrm{MBP}_{87-99}$, suggesting that they promote Th2 cell-type responses [27]. However, T-cell differentiation is dominantly directed by the cytokine milieu and peptide-MHC levels at the time of T-cell activation [31], and EAE immunization protocols purposely induce high level production of T-cell polarization cytokines IL-12 and IL-23 by local antigen-presenting cells, which in turn promote the development of pathogenic Th1 and Th17 cells, respectively [32-34]. It is therefore unclear whether co-administration of cyclic $\mathrm{MBP}_{87-99}$ analogues and $\mathrm{MBP}_{72-85}$ agonist under EAE-inducing conditions [24,26], would permit the differentiation of Th2 cells or iTreg sufficiently to ameliorate disease.

To further investigate the mechanism of disease modulation by three cyclic mutant analogues, cyclo(91-99)[Ala $\left.{ }^{96}\right] \mathrm{MBP}_{87-99}$, cyclo(87-99)[Ala ${ }^{91,96}{ }^{1} \mathrm{MBP}_{87-99}$ and cyclo(87-99)[Arg ${ }^{91}, \mathrm{Ala}^{96}{ }^{9} \mathrm{MBP}_{87-99}$, in the current study we administered them in the $\mathrm{MBP}_{72-85}$-EAE model in Lewis rats using prophylactic (vaccination) and early therapeutic protocols. In this way, we separated the administration of cyclic analogues from that of the disease-inducing agonist in a temporal manner, so that effects due to possible MHC class II binding competition and immune deviation were minimized. We show that all three cyclic analogues ameliorate EAE when administered prophylactically or therapeutically, and that protection is associated with strong T-cell responses to the cyclic analogues coupled with reduced responses to the EAE-inducing antigen $\mathrm{MBP}_{72-85}$. Importantly, longitudinal studies in rats receiving prophylactic cyclo(87-99)[Arg ${ }^{91}$, Ala $\left.{ }^{96}\right] \mathrm{MBP}_{87-99}$, showed that treatment provided lasting and robust protection against EAE, up to the last time point studied with statistically significant differences (day 35 post-administration). These studies provide the first indication that cyclic peptide analogues based on the MS candidate auto-antigen $\mathrm{MBP}_{87-99}$, provide therapeutic and lasting prophylactic protection against EAE through an active mechanism, involving the activation of peptide analogue-specific $T$ cells and memory T-cell formation. It remains to be determined whether the $\mathrm{T}$ cells induced by cyclic peptide analogues show characteristics of peripherally-induced regulatory $\mathrm{T}$ cells, which are known to actively suppress T-cell responses through mechanisms such as the secretion of immunosuppressive soluble factors like TGF-beta and IL-10, and competition for the T-cell growth factor IL-2 [35].

The development of cyclic peptide analogues modeled on the MS candidate auto-antigen $\mathrm{MBP}_{87-99}$, is a promising alternative approach for APL immunotherapy in MS. Such analogues demonstrate properties that might be relevant for MS immunotherapy and provide an alternative approach to linear APLs. Previously, our group showed that they suppress the proliferation of a $\mathrm{CD} 4^{+}$ T-cell line derived from a MS patient, stimulate T-cell responses in peripheral blood monocytes from MS patients inducing Th2 responses when used to immunize mice, show good binding to human HLA-DR4, and show improved stability to proteolysis over linear analogues [24-27]. Furthermore, we show herein that these analogues have the ability to stimulate protective T-cell responses when administered prophylactically or therapeutically in EAE, and induce lasting protection against EAE through an active mechanism. It remains to be determined whether cyclic MBP $87-99$ analogues protect against CNS autoimmunity in the EAE model through the differentiation of iTreg or an alternative immune-regulatory mechanism.

\section{Materials and Methods}

\subsection{Peptide Synthesis, Cyclization and Analysis}

Peptides (Table 2) were synthesized by Fmoc/tBu methodology using the acid-labile 2-chlorotrityl chloride resin (CLTR-Cl) and $N^{\alpha}$-Fmoc (9-fluorenylmethyloxycarboxyl)-protected amino acids as previously described [36-38]. The cyclization procedure was performed as described previously [24,26]. The final linear and cyclic peptides were purified and identified using semi-preparative, reverse phase high performance liquid chromatography (RP-HPLC) and electron spray ionization mass spectrometry (ESI-MS; Supplementary Materials), respectively. The purity of linear and cyclic peptides was more than $95 \%$ as determined by analytical RP-HPLC. 
Table 2. Sequence of studied linear and cyclic myelin basic protein (MBP) peptide analogues.

\begin{tabular}{|c|c|c|}
\hline $\mathbf{a} / \mathbf{a}$ & Peptide Sequence & Short Name \\
\hline 1 & L $^{72}$ PQKSQRSQDENPV 85 (guinea pig) & $\mathrm{MBP}_{72-85}$ \\
\hline 2 & $\mathrm{~V}^{87}$ HFFKNIVTPRTP 99 & $\mathrm{MBP}_{87-99}$ \\
\hline 3 & $\mathrm{~V}^{87}$ HFFA $^{91}$ NIVTA $^{96}$ RTP $^{99}$ & cyclo(87-99)[Ala $\left.{ }^{91,96}\right] \mathrm{MBP}_{87-99}$ \\
\hline 4 & $\mathrm{~V}^{87}$ HFFKNIVTA ${ }^{96}$ RTP $^{99}$ & cyclo(91-99)[Ala $\left.{ }^{96}\right] \mathrm{MBP}_{87-99}$ \\
\hline 5 & $\mathrm{~V}^{87}$ HFFR $^{91}$ NIVTA $^{96}$ RTP $^{99}$ & cyclo(87-99)[Arg ${ }^{91}$, Ala $\left.^{96}\right] \mathrm{MBP}_{87-99}$ \\
\hline
\end{tabular}

\subsection{EAE Induction Evaluation and Tissue Sampling}

Experiments were performed in female Lewis rats of 12 weeks of age. EAE was induced by s.c. tail base injection of $30 \mu \mathrm{g}$ of $\mathrm{MBP}_{72-85}$ dissolved in $100 \mu \mathrm{L}$ saline and emulsified in $100 \mu \mathrm{L}$ complete Freund's adjuvant (CFA) (Sigma-Aldrich, St. Louis, MO, USA) supplemented with $400 \mu \mathrm{g}$ of H37Ra Mycobacterium tuberculosis (Difco, Detroit, MI, USA). Rats were weighed and assessed daily for clinical signs according to the following criteria: 0 , normal; 0.5 , weight loss; 1 , limp tail; 2 , hind limb weakness; 3 , hind limb paralysis; 4 , forelimb weakness; 5 , moribund or dead. Moribund animals were sacrificed. Rats were allowed free access to food and water throughout the experiment. Rats were maintained under conventional conditions in the experimental animal unit of the Hellenic Pasteur Institute. All experimental protocols were evaluated and approved by the Institutional Protocol Evaluation Committee and the national Hellenic authorities (National Health Authority (PKA) licenses EL25BIO011, EL25BIO012 and EL25BIO013) and conformed to EU guidelines.

\subsection{In Vivo Treatment with Cyclic Peptide Analogues}

The cyclic $\mathrm{MBP}_{87-99}$ analogues, cyclo(91-99)[Ala $\left.{ }^{96}\right] \mathrm{MBP}_{87-99}$, cyclo(87-99)[Ala $\left.{ }^{91,96}\right] \mathrm{MBP}_{87-99}$, and cyclo(87-99)[Arg ${ }^{91}, \mathrm{Ala}^{96}{ }^{9} \mathrm{MBP}_{87-99}(500 \mu \mathrm{g})$ were each dissolved in saline and emulsified in $100 \mu \mathrm{L}$ incomplete Freund's adjuvant (IFA) (Sigma-Aldrich, St. Louis, MO, USA) and administered to rats by s.c. tail base injection, at a different site from the immunization site, 2 or 21 days before or 2 days after immunization with $\mathrm{MBP}_{72-85}$ for the induction of EAE.

\subsection{T Cell Proliferation Assay}

Draining lymph node (DLN) cells and splenocytes were isolated from EAE control and analogue-treated rats 10 days after immunization with $\mathrm{MBP}_{72-85}$ and isolated cells were cultured for $72 \mathrm{~h}$ in 96-well plates in RPMI 1640 containing 10\% heat-inactivated FCS, $50 \mu \mathrm{M}$ 2-mercaptoethanol (all Invitrogen Life Technologies, Gaithersburg, MD, USA) and increasing concentrations of $\mathrm{MBP}_{72-85}$ agonist or cyclo(87-99)[Arg ${ }^{91}, \mathrm{Ala}^{96}{ }^{9} \mathrm{MBP}_{87-99}$ analogue. Cells were pulsed with $1 \mu \mathrm{Ci} / 5 \times 10^{5}$ cells $[3 \mathrm{H}]$ thymidine (PerkinElmer, Waltham, MA, USA) for the last $16 \mathrm{~h}$ of culture, and [3H]thymidine incorporation was measured by liquid scintillation counting (Wallac, Turku, Finland). Results are expressed as stimulation index (ratio between radioactivity counts of cells cultured in the presence of $\mathrm{Ag}$ and of cells cultured with medium alone).

\subsection{Histopathology}

Rats were transcardially perfused with ice-cold $4 \%$ paraformaldehyde in PBS under deep anaesthesia. CNS tissues were post-fixed in the same fixative overnight at $4{ }^{\circ} \mathrm{C}$ and processed for standard histopathological analyses using paraffin sections $(3-5 \mu \mathrm{M})$. Inflammation was visualized by staining with haematoxylin-eosin according to standard procedures [39].

\subsection{Statistical Analyses}

All statistical analyses were performed with SigmaStat 3.5 (Systat Software Inc., San Jose, CA, USA) for Windows. All data are given as mean \pm SEM. To determine significant differences between disease in control and treated rats at different time points after immunization 
(Figures 1 and 4), the Mann-Whitney rank sum test was performed. Student's $t$-test was used to compare the inflammatory infiltrates (Figure 2) and $\mathrm{T}$ cell proliferation responses to $\mathrm{MBP}_{72-85}$ and cyclo(87-99)[Arg $\left.{ }^{91}, \mathrm{Ala}^{96}\right]_{\mathrm{MBP}_{87-99}}$ peptide (Figure 3). Values of $p<0.05$ were considered statistically significant.

Supplementary Materials: The supplementary materials are available online.

Acknowledgments: We wish to thank the pharmaceutical company Vianex SA, Greece for their continuous support for MS research studies. This work was financially supported by the European Commission through the NeuroSign project FP7 REGPOT grant No. 264083 and the Hellenic Republic Ministry of Education-General Secretariat of Research \& Technology (GSRT) through the National Action Cooperation project grant "Multiple Sclerosis Therapy" 09SYN-21-609 and the Bilateral R\&T Greece-Israel Collaboration grant "A novel combined approach for the immunotherapy of multiple sclerosis" ISR_3148.

Author Contributions: T.T. and L.P. conceived and designed the experiments; M.E. and V.T. performed the experiments; M.E. and L.P. analyzed the data; I.T. and A.N. contributed in peptide synthesis; T.T. and M.E. edited the manuscript, L.P. wrote the paper.

Conflicts of Interest: The authors declare no conflicts of interest. The founding sponsors had no role in the design of the study; in the collection, analyses, or interpretation of data; in the writing of the manuscript, and in the decision to publish the results.

\section{References}

1. Lassmann, H. Mechanisms of white matter damage in multiple sclerosis. Glia 2014, 62, 1816-1830. [CrossRef] [PubMed]

2. Rangachari, M.; Kuchroo, V.K. Using eae to better understand principles of immune function and autoimmune pathology. J. Autoimmun. 2013, 45, 31-39. [CrossRef] [PubMed]

3. Lopez-Diego, R.S.; Weiner, H.L. Novel therapeutic strategies for multiple sclerosis-A multifaceted adversary. Nat. Rev. Drug Discov. 2008, 7, 909-925. [CrossRef] [PubMed]

4. Cao, Y.; Goods, B.A.; Raddassi, K.; Nepom, G.T.; Kwok, W.W.; Love, J.C.; Hafler, D.A. Functional inflammatory profiles distinguish myelin-reactive T cells from patients with multiple sclerosis. Sci. Transl. Med. 2015, 7, 287ra274. [CrossRef] [PubMed]

5. Martin, R.; Jaraquemada, D.; Flerlage, M.; Richert, J.; Whitaker, J.; Long, E.O.; McFarlin, D.E.; McFarland, H.F. Fine specificity and HLA restriction of myelin basic protein-specific cytotoxic T cell lines from multiple sclerosis patients and healthy individuals. J. Immunol. 1990, 145, 540-548. [PubMed]

6. Pette, M.; Fujita, K.; Kitze, B.; Whitaker, J.N.; Albert, E.; Kappos, L.; Wekerle, H. Myelin basic protein-specific T lymphocyte lines from MS patients and healthy individuals. Neurology 1990, 40, 1770-1776. [CrossRef] [PubMed]

7. Ota, K.; Matsui, M.; Milford, E.L.; Mackin, G.A.; Weiner, H.L.; Hafler, D.A. T-cell recognition of an immunodominant myelin basic protein epitope in multiple sclerosis. Nature 1990, 346, 183-187. [CrossRef] [PubMed]

8. Bielekova, B.; Sung, M.H.; Kadom, N.; Simon, R.; McFarland, H.; Martin, R. Expansion and functional relevance of high-avidity myelin-specific CD4+ T cells in multiple sclerosis. J. Immunol. 2004, 172, 3893-3904. [CrossRef] [PubMed]

9. Wucherpfennig, K.W.; Catz, I.; Hausmann, S.; Strominger, J.L.; Steinman, L.; Warren, K.G. Recognition of the immunodominant myelin basic protein peptide by autoantibodies and HLA-DR2-restricted T cell clones from multiple sclerosis patients. Identity of key contact residues in the B-cell and T-cell epitopes. J. Clin. Investig. 1997, 100, 1114-1122. [CrossRef] [PubMed]

10. Lutterotti, A.; Yousef, S.; Sputtek, A.; Sturner, K.H.; Stellmann, J.P.; Breiden, P.; Reinhardt, S.; Schulze, C.; Bester, M.; Heesen, C.; et al. Antigen-specific tolerance by autologous myelin peptide-coupled cells: A phase 1 trial in multiple sclerosis. Sci. Transl. Med. 2013, 5, 188ra175. [CrossRef] [PubMed]

11. Vergelli, M.; Hemmer, B.; Utz, U.; Vogt, A.; Kalbus, M.; Tranquill, L.; Conlon, P.; Ling, N.; Steinman, L.; McFarland, H.F.; et al. Differential activation of human autoreactive $\mathrm{T}$ cell clones by altered peptide ligands derived from myelin basic protein peptide (87-99). Eur. J. Immunol. 1996, 26, 2624-2634. [CrossRef] [PubMed] 
12. Bielekova, B.; Goodwin, B.; Richert, N.; Cortese, I.; Kondo, T.; Afshar, G.; Gran, B.; Eaton, J.; Antel, J.; Frank, J.A.; et al. Encephalitogenic potential of the myelin basic protein peptide (amino acids 83-99) in multiple sclerosis: Results of a phase II clinical trial with an altered peptide ligand. Nat. Med. 2000, 6, 1167-1175. [CrossRef] [PubMed]

13. Kappos, L.; Comi, G.; Panitch, H.; Oger, J.; Antel, J.; Conlon, P.; Steinman, L. Induction of a non-encephalitogenic type $2 \mathrm{~T}$ helper-cell autoimmune response in multiple sclerosis after administration of an altered peptide ligand in a placebo-controlled, randomized phase II trial. The altered peptide ligand in relapsing ms study group. Nat. Med. 2000, 6, 1176-1182. [CrossRef] [PubMed]

14. Warren, K.G.; Catz, I.; Ferenczi, L.Z.; Krantz, M.J. Intravenous synthetic peptide mbp8298 delayed disease progression in an hla class II-defined cohort of patients with progressive multiple sclerosis: Results of a 24-month double-blind placebo-controlled clinical trial and 5 years of follow-up treatment. Eur. J. Neurol. 2006, 13, 887-895. [CrossRef] [PubMed]

15. Gaur, A.; Boehme, S.A.; Chalmers, D.; Crowe, P.D.; Pahuja, A.; Ling, N.; Brocke, S.; Steinman, L.; Conlon, P.J. Amelioration of relapsing experimental autoimmune encephalomyelitis with altered myelin basic protein peptides involves different cellular mechanisms. J. Neuroimmunol. 1997, 74, 149-158. [CrossRef]

16. Karin, N.; Mitchell, D.J.; Brocke, S.; Ling, N.; Steinman, L. Reversal of experimental autoimmune encephalomyelitis by a soluble peptide variant of a myelin basic protein epitope: $\mathrm{T}$ cell receptor antagonism and reduction of interferon gamma and tumor necrosis factor alpha production. J. Exp. Med. 1994, 180, 2227-2237. [CrossRef] [PubMed]

17. De Magistris, M.T.; Alexander, J.; Coggeshall, M.; Altman, A.; Gaeta, F.C.; Grey, H.M.; Sette, A. Antigen analog-major histocompatibility complexes act as antagonists of the $\mathrm{T}$ cell receptor. Cell 1992, 68, 625-634. [CrossRef]

18. Sloan-Lancaster, J.; Evavold, B.D.; Allen, P.M. Induction of T-cell anergy by altered T-cell-receptor ligand on live antigen-presenting cells. Nature 1993, 363, 156-159. [CrossRef] [PubMed]

19. Evavold, B.D.; Allen, P.M. Separation of IL-4 production from th cell proliferation by an altered T cell receptor ligand. Science 1991, 252, 1308-1310. [CrossRef] [PubMed]

20. Brocke, S.; Gijbels, K.; Allegretta, M.; Ferber, I.; Piercy, C.; Blankenstein, T.; Martin, R.; Utz, U.; Karin, N.; Mitchell, D.; et al. Treatment of experimental encephalomyelitis with a peptide analogue of myelin basic protein. Nature 1996, 379, 343-346. [CrossRef] [PubMed]

21. Nicholson, L.B.; Kuchroo, V.K. Manipulation of the Th1/Th2 balance in autoimmune disease. Curr. Opin. Immunol. 1996, 8, 837-842. [CrossRef]

22. Tapeinou, A.; Matsoukas, M.T.; Simal, C.; Tselios, T. Review cyclic peptides on a merry-go-round; towards drug design. Biopolymers 2015, 104, 453-461. [CrossRef] [PubMed]

23. Tselios, T.; Daliani, I.; Deraos, S.; Thymianou, S.; Matsoukas, E.; Troganis, A.; Gerothanassis, I.; Mouzaki, A.; Mavromoustakos, T.; Probert, L.; et al. Treatment of experimental allergic encephalomyelitis (EAE) by a rationally designed cyclic analogue of myelin basic protein (MBP) epitope 72-85. Bioorg. Med. Chem. Lett. 2000, 10, 2713-2717. [CrossRef]

24. Tselios, T.; Apostolopoulos, V.; Daliani, I.; Deraos, S.; Grdadolnik, S.; Mavromoustakos, T.; Melachrinou, M.; Thymianou, S.; Probert, L.; Mouzaki, A.; et al. Antagonistic effects of human cyclic mbp(87-99) altered peptide ligands in experimental allergic encephalomyelitis and human T-cell proliferation. J. Med. Chem. 2002, 45, 275-283. [CrossRef] [PubMed]

25. Matsoukas, J.; Apostolopoulos, V.; Kalbacher, H.; Papini, A.M.; Tselios, T.; Chatzantoni, K.; Biagioli, T.; Lolli, F.; Deraos, S.; Papathanassopoulos, P.; et al. Design and synthesis of a novel potent myelin basic protein epitope 87-99 cyclic analogue: Enhanced stability and biological properties of mimics render them a potentially new class of immunomodulators. J. Med. Chem. 2005, 48, 1470-1480. [CrossRef] [PubMed]

26. Deraos, G.; Rodi, M.; Kalbacher, H.; Chatzantoni, K.; Karagiannis, F.; Synodinos, L.; Plotas, P.; Papalois, A.; Dimisianos, N.; Papathanasopoulos, P.; et al. Properties of myelin altered peptide ligand cyclo(87-99)(Ala91,Ala96)MBP87-99 render it a promising drug lead for immunotherapy of multiple sclerosis. Eur. J. Med. Chem. 2015, 101, 13-23. [CrossRef] [PubMed]

27. Katsara, M.; Deraos, G.; Tselios, T.; Matsoukas, M.T.; Friligou, I.; Matsoukas, J.; Apostolopoulos, V. Design and synthesis of a cyclic double mutant peptide (cyclo(87-99)[A91,A96]MBP87-99) induces altered responses in mice after conjugation to mannan: Implications in the immunotherapy of multiple sclerosis. J. Med. Chem. 2009, 52, 214-218. [CrossRef] [PubMed] 
28. Katsara, M.; Deraos, G.; Tselios, T.; Matsoukas, J.; Apostolopoulos, V. Design of novel cyclic altered peptide ligands of myelin basic protein MBP83-99 that modulate immune responses in SJL/J mice. J. Med. Chem. 2008, 51, 3971-3978. [CrossRef] [PubMed]

29. Mantzourani, E.D.; Platts, J.A.; Brancale, A.; Mavromoustakos, T.M.; Tselios, T.V. Molecular dynamics at the receptor level of immunodominant myelin basic protein epitope 87-99 implicated in multiple sclerosis and its antagonists altered peptide ligands: Triggering of immune response. J. Mol. Graph. Model. 2007, 26, 471-481. [CrossRef] [PubMed]

30. Mantzourani, E.D.; Mavromoustakos, T.M.; Platts, J.A.; Matsoukas, J.M.; Tselios, T.V. Structural requirements for binding of myelin basic protein (MBP) peptides to MHC II: Effects on immune regulation. Curr. Med. Chem. 2005, 12, 1521-1535. [CrossRef] [PubMed]

31. Zhu, J.; Yamane, H.; Paul, W.E. Differentiation of effector CD4 T cell populations (*). Annu. Rev. Immunol. 2010, 28, 445-489. [CrossRef] [PubMed]

32. Cua, D.J.; Sherlock, J.; Chen, Y.; Murphy, C.A.; Joyce, B.; Seymour, B.; Lucian, L.; To, W.; Kwan, S.; Churakova, T.; et al. Interleukin-23 rather than interleukin-12 is the critical cytokine for autoimmune inflammation of the brain. Nature 2003, 421, 744-748. [CrossRef] [PubMed]

33. O'Garra, A.; Arai, N. The molecular basis of T helper 1 and T helper 2 cell differentiation. Trends Cell Biol. 2000, 10, 542-550. [CrossRef]

34. Lee, Y.; Awasthi, A.; Yosef, N.; Quintana, F.J.; Xiao, S.; Peters, A.; Wu, C.; Kleinewietfeld, M.; Kunder, S.; Hafler, D.A.; et al. Induction and molecular signature of pathogenic Th17 cells. Nat. Immunol. 2012, 13, 991-999. [CrossRef] [PubMed]

35. Verhagen, J.; Wegner, A.; Wraith, D.C. Extra-thymically induced T regulatory cell subsets: The optimal target for antigen-specific immunotherapy. Immunology 2015, 145, 171-181. [CrossRef] [PubMed]

36. Friligou, I.; Papadimitriou, E.; Gatos, D.; Matsoukas, J.; Tselios, T. Microwave-assisted solid-phase peptide synthesis of the 60-110 domain of human pleiotrophin on 2-chlorotrityl resin. Amino acids 2011, 40, 1431-1440. [CrossRef] [PubMed]

37. Friligou, I.; Rizzolo, F.; Nuti, F.; Tselios, T.; Evangelidou, M.; Emmanouil, M.; Karamita, M.; Matsoukas, J.; Chelli, M.; Rovero, P.; et al. Divergent and convergent synthesis of polymannosylated dibranched antigenic peptide of the immunodominant epitope MBP(83-99). Bioorg. Med. Chem. 2013, 21, 6718-6725. [CrossRef] [PubMed]

38. Ieronymaki, M.; Androutsou, M.E.; Pantelia, A.; Friligou, I.; Crisp, M.; High, K.; Penkman, K.; Gatos, D.; Tselios, T. Use of the 2-chlorotrityl chloride resin for microwave-assisted solid phase peptide synthesis. Biopolymers 2015, 104, 506-514. [CrossRef] [PubMed]

39. Nicolussi, E.M.; Huck, S.; Lassmann, H.; Bradl, M. The cholinergic anti-inflammatory system limits $\mathrm{T}$ cell infiltration into the neurodegenerative CNS, but cannot counteract complex CNS inflammation. Neurobiol. Dis. 2009, 35, 24-31. [CrossRef] [PubMed]

Sample Availability: Samples of all the synthesized peptides described in this manuscript are freely available from the authors.

(C) 2018 by the authors. Licensee MDPI, Basel, Switzerland. This article is an open access article distributed under the terms and conditions of the Creative Commons Attribution (CC BY) license (http:/ / creativecommons.org/licenses/by/4.0/). 